\title{
Reivindicación de la Ciencia. La enseñanza de las Ciencias Naturales
}

\section{Mercedes de Unamuno Adarraga}

Arbor CLXXIII, 681 (Septiembre 2002), 165-181 pp.

Es importante reivindicar el papel de la Ciencia, el papel del conocimiento en la enseñanza. Se insiste mucho en la actualidad en la formación para los valores, pero parece claro que la adquisición de éstos debe ser consecuencia de una formación -en la que el aspecto intelectual tiene gran importancia-y no de un adoctrinamiento. La enseñanza de la Ciencia proporciona logros fundamentales en la formación humana, logros tan esenciales como aprender a pensar, desarrollar la creatividad y experimentar el placer de conocer. Y esto sólo se conseguirá con el instrumento más esencial de la Ciencia: su método. Plantear bien los problemas, elaborar conjeturas que ofrezcan soluciones a los problemas, criticar esas conjeturas y someterlas a control supone distinguir entre Ciencia y dogma. Todo ello -es decir, este enfoque-debería tenerse muy presente a la hora de elaborar el currículo de la enseñanza obligatoria.

Existe en la actualidad un grave peligro que acecha a la enseñanza: el paulatino abandono del conocimiento, la escasa valoración de la Ciencia en todas sus facetas y, en consecuencia, la subvaloración de la formación intelectual.

El problema, aunque ahora agudizado, tampoco es nuevo. Ya Unamuno en 1917 dice: «Es como los que al exaltar la educación sólo piensan en deprimir la instrucción, o los que, fingiendo poner sobre todo la for- 
mación del carácter, en rigor se proponen limitar la adquisición de la Ciencia. !Es tan peligrosa ésta y es tan rebelde la inteligenciaj». Parecen palabras actuales. Parece la réplica a esa infravaloración actual del conocimiento, a las, casi podríamos llamar, ¿consignas? sobre la educación para los valores, como si el establecimiento de una escala de valores no fuera fruto de una maduración, de una reflexión personal. Una educación para los valores que no sea consecuencia de una formación integral, en la que la formación intelectual tiene una parte muy importante, corre el riesgo de convertirse en un adoctrinamiento.

El conocimiento, la Cultura, la Ciencia, no son valores apreciados en la Sociedad. La Cultura se tacha muchas veces de elitista. Y, quizá para deshacer esa concepción, se manejan en la Sociedad las formas más anecdóticas, digamos, de la Cultura, las más periféricas, las más banales.

La Ciencia se presenta, con frecuencia, como un dogma. Muchas veces, incluso, por los propios especialistas. Así, multitud de libros de texto, al explicar la teoría de la evolución biológica, aducen pruebas (pruebas embriológicas o morfológicas o paleontológicas...). Existen, evidentemente, muchos apoyos empíricos en los que se sustenta esta teoría, pero nunca pruebas. Se trata de una teoría científica, no de un dogma.

Existen también, en la actualidad, corrientes (y dentro del mundo científico) que suponen una total contradicción al espíritu de la Ciencia. Me refiero a esas corrientes que valoran las interpretaciones apriorísticas, como puede ser la diferencia femenina (¿racionalidad masculina y racionalidad femenina?) o incluso la diferencia racial. El que estas corrientes tengan éxito, cuando no se basan en principio teórico alguno, sino en determinadas estadísticas, que no se analizan, supone una puerta abierta a la pseudociencia. Pues, es bien sabido, que en Ciencia las evidencias no las dan los datos sino las teorías, las interpretaciones de los datos. Estas peligrosas corrientes pseudocientíficas podría pensarse que pretenden suplantar el campo de la Ciencia.

Voy a citar un ejemplo, recogido de un artículo publicado el 19 de junio de 1997 en el diario Le Monde. Se trata de un curioso proceso, en el que un profesor de «Educación Cristiana» de la Universidad de Melbourne, partidario de una interpretación literal de La Biblia, ha sido demandado por un profesor de Geología de la misma Universidad, acusado de fraude científico. El doctor en «Educación Cristiana» aporta ¿pruebas científicas?: los restos del Arca de Noé, que él afirma haber encontrado sobre el Monte Ararat, en Turquía, en 1992.

El juez de la corte federal de Sydney ha estimado que el asunto no entra en el cuadro de sus competencias. Pero si este pintoresco asunto re- 


\section{Reivindicación de la Ciencia}

sulta relevante es, como afirma el profesor de Geología (que dice haber recibido el sostén de muchos hombres de Iglesia, de distintas creencias), por la alarmante importancia que están tomando estas tesis dentro de los medios universitarios. Tesis que suponen una marcha atrás, nada menos que hasta el origen de la Ciencia, que se originó, precisamente, al separarse de otras formas de entender el mundo. Intentar conjugar creencias, del tipo que sean, con planteamientos científicos, es crear confusionismo, es hacer pseudociencia.

Bertrand Russell, en el prólogo de La perspectiva científica (1983), dice: «El conflicto entre Galileo y la Inquisición no es meramente el conflicto entre el libre pensamiento y el fanatismo o entre la Ciencia y la religión; es, además, un conflicto entre el espíritu de inducción y el espíritu de deducción. Los que creen en la deducción como método para llegar al conocimiento se ven obligados a tomar sus premisas de alguna parte, generalmente de un libro sagrado». Esta inteligente reflexión es válida para el contexto histórico de Galileo. En la actualidad, en la Ciencia, existe inducción y también deducción, pero ésta última se hace a partir del cuerpo de conocimiento científico que se ha construido como consecuencia de la inducción. En la actualidad se pretende entender la Naturaleza sólo con los datos que la propia Naturaleza proporciona. Es lo que llama Monod (19) el «postulado de objetividad de la Naturaleza». Que la objetividad total sea imposible, como la propia Ciencia ha reconocido, no quiere decir que no se siga intentando conseguir las mayores cotas posibles de objetividad. Toda la Historia de la Ciencia es un largo camino desde la subjetividad, el antropocentrismo, hasta la máxima objetividad posible.

Por supuesto, de la misma forma que ninguna idea apriorística extracientífica ha de introducirse en la Ciencia, tampoco puede apoyarse ni combatirse ninguna idea ajena a la Ciencia con principios científicos. Tan deplorable es la pseudociencia como el cienticismo. Y aquí aprovecho la oportunidad para reivindicar el nombre de Darwin, que se usa tantas veces en vano, cuando se habla de darwinismo social. La teoría darwiniana de la selección natural, contrastada para tantos casos, es válida única y exclusivamente dentro del mundo vivo.

\section{Problemas de la Escuela y de la Sociedad}

Esta imagen deteriorada de la Ciencia, de la Cultura, esta falta de aprecio por el conocimiento, evidentemente repercute en la Escuela. Y es lógico que sea así. La Escuela no es una entidad cerrada en sí misma, 
sino que es un subsistema dentro del sistema social. Y sus relaciones con la Sociedad son profundos y se retroalimentan.

Todos los problemas de la Sociedad inciden en la Escuela. Pero pretender que ésta los resuelva, no sólo es imposible, sino que es perder la perspectiva de cuál es su función. El paro, la violencia, etc. son problemas que la Escuela no puede resolver. E intentar resolverlos puede, por el contrario, incrementarlos. Ante la falacia del fracaso escolar se rebajan los niveles de exigencia. $\mathrm{Y}$ así, la igualdad de oportunidades que la Sociedad dice defender, es cada vez menor, dando lugar a un elitismo mucho mayor de las clases pudientes y a un total hundimiento de la Escuela pública.

Otro enemigo de la formación intelectual es el agobio que parece representar en la actualidad para nuestras autoridades educativas el reto del enorme desarrollo tecnológico de nuestro tiempo. Pero preparar para un mundo en constante transformación, no significa adiestrar en innovaciones tecnológicas, quizá ya superadas cuando el alumno termine sus estudios. Significa, más bien, formar personas dotadas de una estructura mental que les permite adecuarse a cualquier mundo posible. La otra alternativa tiene el riesgo de formar analfabetos tecnológicos.

\section{2. ¿Qué debe enseñarse en el Bachillerato y en Primaria?}

Ante esta situación de empobrecimiento intelectual en la Escuela, afortunadamente, se están levantando ya voces de alarma. Y, así, en el número de agosto de 1996 de la revista Investigación y Ciencia varios profesores contestan a la pregunta «¿qué debe enseñarse en el bachillerato?». El profesor Antonio Domínguez Ortiz, Premio Príncipe de Asturias, a propósito de la enseñanza de la Historia, dice: «se intenta diluir su contenido en un espacio vago, de contornos mal definidos, en el que disciplinas más o menos afines intentan cobijarse y convivir bajo el rótulo de ¿ciencias sociales?».

¿Qué diría Domínguez Ortiz si supiera -quizá lo sepa-que en la enseñanza primaria la Historia se diluye y se desdibuja aún más, puesto que ese espacio vago amplía y difumina sus contornos hasta hacer sitio en él también a las Ciencias de la Naturaleza: Física, Química, Geología y Biología? Es el espacio confuso que recibe el nombre de «Medio». «Conocimiento del Medio» es lo que queda de una serie de Ciencias específicas y precisas. Ciencias entre las que existen, ciertamente, conexiones que sería muy interesante establecer. Pero eso debería hacerse en un segundo nivel, cuando se conociera sencilla pero claramente de 


\section{Reivindicación de la Ciencia}

qué trata cada una de ellas. Objetivo imposible con este planteamiento confuso.

En el mismo artículo de Investigación y Ciencia, el profesor Francisco Rodríguez Adrados se lamenta tanto de la desaparición del «Latín para todos» en el Bachillerato como de la oposición de Ciencias y Letras. Y añade: «Ahora han sido tanto las ciencias como las letras (y el latín y el griego sobre todo) las que han sufrido el embate de las ¿nuevas humanidades? Y de un pedagogismo igualitario por lo bajo que sólo propone una cultura elementalísima y luego especialismo.

Y es de subrayar cómo un especialista en lenguas clásicas se lamenta del deterioro de la enseñanza no sólo de las Letras sino también de las Ciencias. Es admirable que sea precisamente Rodríguez Adrados quien señale la importancia de la formación científica, que es, no sólo complemento de la formación humanística, sino, casi podríamos decir, parte de ella. Nuestra sociedad confunde, en general, la Ciencia con la Técnica, como si la Ciencia no fuera una creación humana teórica, un intento de entender el mundo (aunque, naturalmente, de ese entendimiento se extraigan también consecuencias que redunden en un beneficio para la $\mathrm{Hu}$ manidad).

Y resulta muy estimulante la coincidencia entre Rodríguez Adrados, especialista del mundo clásico y un científico como Pedro García Barreno, que en su conferencia «Educación y Formación de cara al siglo XXI: el papel de la Ciencia» (dictada dentro de la Jornada científica organizada por el Foro Cultural «Pablo Montesino» en la Facultad de Educación de la Universidad Complutense de Madrid, el 23 de mayo de 1999) dice: «Se necesita un concepto amplio de cultura que incluya las Ciencias naturales, la Tecnología y las Humanidades, y que se revele como la totalidad del trabajo y formas de vida humana. No hay nada que impida contemplar todas las Ciencias, incluidas las Humanidades, como expresiones particulares de la misma racionalidad que ha creado el mundo moderno. Esta racionalidad se expresa de varias formas, pero nada nos obliga a dividirlas en dos ni tres culturas».

A la pregunta «¿qué enseñar en el bachillerato?» de la revista Investigación y Ciencia, contestan el profesor Antonio García Bellido, de Biología, y los profesores franceses Pierre Gilles de Gennes y Jean Marie Lehn, Premios Nobel de Física y Química, respectivamente. Las reflexiones de García Bellido y P. G. De Gennes son prácticamente iguales. Ambos marcan el énfasis en la necesidad de un estudio fundamental de los aspectos básicos de cada Ciencia, viniendo todo lo demás por añadidura. Así, García Bellido dice, refiriéndose a la Biología: «El conocimiento de los aspectos fundamentales es necesario para fundamentar nuestra acti- 
vidad diaria, para entender entre otras muchas cosas las causas de las enfermedades que nos afectan o las bases genéticas de nuestro comportamiento». Y de Gennes: «¿Qué hay que enseñar? Un poderoso grupo de presión instalado en el Ministerio de Educación Nacional opina que la escuela debe enseñar las técnicas modernas. El programa de física, en segundo, presenta los amplificadores operacionales, los altavoces y cierto número de aparatos similares. En mi opinión esto es catastrófico, porque se habla de joules y watios sin saber qué es la energía (...) Lo que hoy se propone confunde la técnica con la ciencia».

No puedo evitar citar otra vez a Unamuno, que en el año 1915 decía sustancialmente esto mismo, en un artículo titulado «Nuestros pedagogos»: «El maestro debe enseñar todo lo que sepa y debe saber todo lo que pueda. El niño de la escuela tiene derecho a que se le den nociones fundamentales de matemáticas, de física, de química, de historia natural, de historia, de literatura, etc. La cuestión estriba en que sean fundamentales (...) Hay, en efecto, un prejuicio extendido de que lo fundamental se opone a lo elemental. Y es todo lo contrario (...) En la escuela no hay que hacer siderúrgicos, ni plateros, ni boticarios, sino hombres».

Y Jean Marie Lehn dice: «Las artes expresan uno de los aspectos de la creatividad humana. Las ciencias otro (...) Mucho es lo que hay que hacer para no centrarse en el formalismo: la comprensión de que la química revela coherencias en la naturaleza, regularidades, leyes, constituye un gran placer».

\section{Logros que proporciona el conocimiento}

Esta reflexión sobre el placer que proporciona el conocimiento la hace también Darwin (1876) en su autobiografía: «tenía mucho entusiasmo por todo aquello que me interesaba, y sentía un placer especial en la comprensión de cualquier materia o cosa compleja. Un profesor particular me explicó Euclides, y recuerdo claramente la intensa satisfacción que me proporcionaban las claras demostraciones geométricas».

Aquí se refiere Darwin todavía a su etapa de estudiante en Shrewsbury, su ciudad natal. De sus estudios de Cambridge dice: «Para el diploma final de B.A. (Bachelor of Arts) repasé mis clásicos, así como un poco de álgebra y de Euclides: este último me proporcionó un enorme placer, como ya me había sucedido en la escuela».

Podemos sacar muy claras consecuencias. La importancia del estudio fundamental, la necesidad de lo fundamental en lo elemental. La necesidad de los fundamentos para poder entender las derivaciones, las aplica- 
ciones, las consecuencias, lo que significa, por supuesto, relacionar, es decir, aprender a pensar. Y también la Ciencia como fuente de creatividad y el conocimiento como fuente de placer.

Si la Ciencia pretende entender el mundo, entender al hombre y todas sus manifestaciones, eso significa buscar interpretaciones. La tan traída y llevada «enseñanza significativa» cobra aquí todo su sentido, puesto que buscar significados es interpretar. Y buscar significados es desarrollar la creatividad y desarrollar la racionalidad: aprender a pensar. Se aprende a pensar pensando. En cuanto al placer de conocer es el placer de comprender. Y este placer será tanto mayor cuanto más esfuerzo haya costado desentrañar el misterio de que se trate.

Aprender a pensar, desarrollar la creatividad y experimentar placer son, pues, tres logros que proporciona el conocimiento. Y esto es así gracias a un instrumento conceptual fundamental que es el método de la Ciencia. Reivindicar el conocimiento significa reivindicar el método.

\section{El binomio Ciencia-Método}

Como dice Mario Bunge (1975), «conocimiento científico es el que se ha obtenido mediante el método de la ciencia». Y también «si la sustancia (objeto) no es lo distintivo de la ciencia, entonces tiene que serlo la forma (el procedimiento): el método».

Que el objeto no es lo distintivo de la Ciencia está claro. En Biología, por ejemplo, se pueden estudiar seres vivos (el objeto) desde un punto de vista descriptivo o utilitario -plantas medicinales o venenosas o comestibles, etc.-. Mientras no se establezcan hipótesis, teorías explicativas, interpretaciones, no se puede hablar de ciencia. La Ciencia no es una relación de datos sino un entramado de interpretaciones. Tampoco el objetivo de entender, de buscar representaciones de la realidad es lo distintivo de la Ciencia. El mismo objetivo tiene el mito.

El binomio Ciencia-Método es inseparable. No insistiría tanto en un aspecto que parece tan claro si no fuera porque ahora también está de moda denigrar el método. Y no me refiero a filósofos de la Ciencia que, aunque se proclaman contra el método, realmente lo que cuestionan es la posibilidad de una determinada estructura de la Ciencia y señalan las incoherencias de la misma. Y esto, como toda provocación intelectual, es muy saludable. Que la Ciencia presenta incoherencias, que probablemente nunca se llegará a un producto acabado es innegable. El único producto intelectual totalmente definitivo y coherente es el mito. 
A lo que me refiero al hablar de la moda contra el método es a corrientes existentes dentro de la enseñanza. Y a la calificación de rigidez que se aplica, a veces, al método de la Ciencia. Pero esto es desvirtuar su significado. El método es un valiosísimo instrumento de racionalidad que sería lamentable abandonar. Plantear problemas, buscar datos relevantes para poder resolverlos, analizar estos datos, arriesgar conjeturas, criticarlas, matizarlas, reelaborarlas de manera que den lugar a nuevos problemas (...) Todo ello es no sólo un ejercicio de racionalidad sino también, y de una manera muy evidente, de creatividad. Una creatividad que esté sometida a reglas. No todo vale. No se trata de ciencia-ficción. Las conjeturas, las explicaciones han de ser sometidas a contrastación. No se trata de inventar mundos posibles, sino de interpretar el único que conocemos. Es decir, la creatividad se une al rigor intelectual en una perfecta combinación entre razonamiento lógico, creatividad y disciplina mental. Sin olvidar que esta racionalidad, que esta creatividad es una fuente de placer. Es importante en la Escuela conjugar estos dos ejes que hay quien se empeña en considerar contradictorios -racionalidad y placer-, cuando no lo son en absoluto. Pero, para ello, es necesario seleccionar los problemas a tratar.

\section{Aplicación del método de la Ciencia en la enseñanza}

Está claro que no se trata, en absoluto, de que los alumnos hagan en la Escuela investigación científica. Pero está fuera de toda duda que los alumnos preguntan. Un objetivo de la Escuela es satisfacer la curiosidad de los niños y, sobre todo, despertársela.

Ciertamente, los alumnos plantean preguntas demasiado ambiciosas, comparables a las que el hombre se planteó en los orígenes del conocimiento, preguntas a las que se ajustan respuestas acabadas, míticas. Pero esas preguntas pueden remodelarse, pueden fraccionarse en otras más sencillas, es decir, se pueden transformar en preguntas pertinentes a las que poder aplicar el método.

A este respecto puede recordarse que si Mendel (1866) alcanzó unos resultados tan sorprendentes para su época fue muy especialmente por la forma en que planteó el problema. Una época en que no sólo no se conocía mecanismo genético alguno, sino que ni siquiera se conocían los cromosomas, y los planteamientos sobre el misterio de la herencia eran del tipo de los que hacen los niños: ¿en qué consiste la herencia?, ¿qué razón hay para que los hijos se parezcan a sus padres?, u otras semejantes. 


\section{Reivindicación de la Ciencia}

Mendel formuló, por el contrario, una pregunta pertinente: ¿cómo pasan de una generación a otra determinados caracteres -color, estructura de la semilla, longitud del tallo, etc.- en Pisum sativum (guisante)? Pregunta que, a diferencia de las anteriores, podía ser tratada por el método experimental y fue, a su vez, fuente de nuevas preguntas pertinentes. Pues bien, siguiendo a Mendel, no es tan complicado pensar cuáles son las preguntas, cuáles son los problemas pertinentes a cada nivel. $\mathrm{O}$, dicho en otras palabras, ¿cómo podemos llegar a lo fundamental tratándolo de una manera elemental?

Voy a seguir utilizando ejemplos de Biología, por ser mi campo, pero es evidente que cuando hablo de conocimiento me refiero a todo el conocimiento humano. Y es también evidente que las reflexiones que se pueden hacer desde una Ciencia, mutatis mutandis, son extrapolables a todas las ramas del saber.

Una de las preguntas que más hacen los niños es ¿por qué?: ¿por qué lloramos?, ¿por qué late el corazón? Preguntas excesivamente ambiciosas y complejas. Hay que ser muy cautos en Biología en cuanto a la causalidad. Pero estos '¿por qué?' pueden transformarse en '¿para qué?': ¿para qué sirven las lágrimas?, ¿para qué late el corazón?, con lo que no sólo tenemos preguntas pertinentes, preguntas para las que podemos buscar interpretaciones, sino que con ellas llegamos a un aspecto fundamental en Biología: el concepto de función biológica, la constatación de que cada actividad vital desempeña un papel al servicio del organismo.

Naturalmente que en la Escuela se buscarán las funciones a nivel macroscópico, aquéllas cuya observación puede hacerse a ojo desnudo. Buscaremos en lo elemental, lo fundamental. Merece la pena reflexionar sobre el término función, en el que se relacionan dos variables: una, la utilidad -el papel- que desempeña el acto fisiológico, la variables principal, y una variable subordinada, que es la estructura. Si el corazón sirve para recoger sangre y volverla a lanzar, toda su estructura tiene una clara adecuación para esa función. Si la mano sirve para agarrarse a los árboles la estructura tiene una clarísima adecuación para ello.

Encontrar la relación entre la estructura y la función es, evidentemente, una forma de creatividad. Y claramente derivado del concepto de función está el concepto de adaptación. Concepto -hipótesis- fundamental también en Biología. Cuando un niño contempla -en una fotografía, en una diapositiva- la estructura de las patas del topo y las del grillotopo o alacrán cebollero (un insecto próximo al grillo que excava madrigueras en el suelo) podrá encontrar fácilmente la clarísima semejanza de estas patas con las excavadoras que él conoce de las obras: el modelo es 
el mismo. Puede inferirse que si la estructura es la misma la función también lo será.

$\mathrm{Y}$ ¿cómo no relacionar la oruga de la mariposa hipócrita, de rayas amarillas y negras con las señales de tráfico? De donde puede sacarse la interpretación de que esta oruga saca alguna ventaja, no de camuflarse sino de exhibirse. Interpretación que se reforzará con otros datos, como el hecho de ser venenosa. De la misma forma, las aletas interdigitales del pato o de la rana son comparables con las aletas que usan los submarinistas.

Pues bien, todo ello supone hacer inferencias, es decir, racionalidad. $Y$ también creatividad, ya que una forma de creatividad es descubrir implícitos. Por cierto que tanto el ejemplo del topo como el de las aletas interdigitales del pato son ejemplos que utiliza Lamarck (1809). También Darwin (1859) utiliza el concepto de adaptación (la adecuación de las estructuras a las funciones) como uno de los puntos de partida de su teoría. La diferencia entre ambos es que Lamarck postuló, para explicarlo, mecanismos apriorísticos, vitalistas, no sólo incontrastables sino incluso inescrutables.

Funcionalidad, adaptación, coherencia en el mundo vivo, son aspectos fundamentales en Biología que pueden estudiarse de una forma elemental. Toda esta forma de creatividad, de interpretar, de establecer relaciones lógicas, enseña a pensar. Y la comprensión del mundo vivo, de su coherencia, puede producir placer: el placer de conocer.

\section{El aprendizaje (y el placer de descubrir) nunca se termina}

Llegado a este punto voy a tomarme la libertad de contar una experiencia personal que, aunque insignificante, me parece ilustrativa. Llevaba yo muchos años explicando el significado de las plantas como organismos terrestres, significado que es muy sencillo descubrir: las plantas representan un nivel de organización mucho más simple que el de los animales, y es, por tanto, relativamente sencillo entender cómo su evolución ha estado, a grandes líneas, determinada sólo por la enorme presión del ambiente terrestre. Y así si pensamos en las complicaciones adquiridas desde sus supuestos antepasados, las algas, todas pueden interpretarse como adaptaciones a la vida terrestre.

El nivel de organización de las algas es bastante sencillo dentro del mundo vivo: nivel celular. Las algas son protistas fotosintéticos. En su medio acuático tienen resueltos todos los problemas: flotan en el agua gracias al empuje ascensional de ésta, reciben energía solar y el dióxido 


\section{Reivindicación de la Ciencia}

de carbono con las demás sustancias que necesitan están disueltos en el agua. Su estructura laminar, con todas las células semejantes, les permite un intercambio eficaz con su ambiente acuático.

Vivir en tierra -fuera del agua- plantea una serie de problemas y ya no es posible una organización tan sencilla. Las plantas tienen tejidos, todos ellos en relación con las condiciones del ambiente terrestre. En primer lugar, tejidos de revestimiento que evitan la evaporación del agua: epidermis en el vegetal herbáceo y súber o corcho en el leñoso. Puesto que ya no existe absorción por todo el cuerpo -si se evita la salida también se evita la posible entrada- se precisan tejidos absorbentes en la raíz, el órgano que se encuentra en contacto con la humedad del suelo. También existen tejidos conductores por donde circula la solución acuosa del suelo hasta las hojas y de la hoja al resto de la planta. Y hay también tejidos de sostén, fibras que mantienen erguida la planta. Está claro que todos estos tejidos, todas estas estructuras carecerían de sentido en el alga acuática.

La mayor complejidad de las plantas se encuentra en sus órganos reproductores: las flores. Las plantas sin flores tienen como las algas, de las que se supone descienden, esporas resistentes a la desecación. Pero en cuanto a la reproducción gamética-sexual-siguen ligadas al agua. El gameto masculino es una célula desnuda y provista de flagelos que ¿nada? hasta el aparato reproductor femenino, sin riesgo de desecación en un ambiente húmedo. Por eso los grupos más primitivos de plantas, hasta los helechos, siguen ligados a ambientes húmedos.

En las plantas con flores el gameto masculino se encuentra dentro del grano de polen, que es una espora y, como toda espora, dotado de cubiertas impermeables. Cuando el grano de polen llega al estigma de la flor polinizada, germina en contacto con la humedad del estigma, de la misma forma que la espora del moho del pan -por ejemplo- germina en contacto con la humedad del pan. Esta germinación en el estigma supone la formación de un tubo polínico, dentro del cual se encuentra el gameto masculino que llega así hasta el gameto femenino del ovario, con el que se fusiona, teniendo lugar la fecundación. Hasta aquí puede decirse que es lo que ya tantas veces había explicado, y que sirve como un hermoso ejemplo de la coherencia del mundo vivo y de su adecuación al medio.

Un buen día me di cuenta del claro paralelismo que puede establecerse entre este tubo polínico y el órgano copulador de los animales. En los reptiles, por ejemplo, como primeros vertebrados verdaderamente terrestres, existe órgano copulador en el macho, mientras no existe en anfibios ni en peces. El descubrimiento de este caso de convergencia adaptativa -el descubrimiento de este implícito- que una vez descifrado parece tan evidente, me costó varios años. 
Si he contado esta pequeña experiencia personal es para insistir en la idea de que la creatividad, como cualquier otra capacidad, se desarrolla. $Y$ puede servir también para subrayar que nunca se acaba de saber aquello que estudiamos, que siempre puede haber mayores niveles de comprensión y de profundidad en todo conocimiento. Por ello son de una gran ligereza las afirmaciones, que a veces se escuchan, de que no hace falta estudiar conocimientos, puesto que ya vienen en los libros.

Por último, con relación a mi vivencia personal, quiero añadir que el descubrimiento de ese paralelismo entre la fecundación interna de animales y plantas que acabo de relatar, me produjo una intensa satisfacción.

\section{Crítica del currículo de Ciencias en la Educación Primaria}

Como muestra del poco valor dado al conocimiento en las orientaciones de la enseñanza actual, tenemos el currículo de Educación Primaria, recogido en el Real Decreto 1344/1991, de 6 de septiembre, en el que, a manera de ejemplo, voy a considerar la parte concerniente a Biología. Comienzan los contenidos de Conocimiento del medio natural, social y cultural con «1. El ser humano y la salud», que se describe como sigue:

\section{EL SER HUMANO Y LA SALUD}

\section{Conceptos}

El hombre y la mujer como seres vivos. Los procesos de crecimiento y transformación del cuerpo a lo largo del acto vital (peso, talla, dentición, cambios puberales, etc.).

Aspectos básicos de las funciones de relación (sensaciones y movimientos), nutrición (digestión, circulación, respiración y excreción) y reproducción. Identificación y localización de los principales órganos y aparatos.

La salud

Factores y prácticas sociales que favorecen o perturban la salud (deporte, descanso, tabaquismo, alcoholismo, contaminación, ocio y diversiones, condiciones de vida humanas, etc.).

Usos y costumbre en la alimentación y sus repercusiones en la salud.

Seguridad y primeros auxilios.

Actividades destinadas al propio cuidado personal en relación a la alimentación, la higiene, el vestido y los objetos de uso individual.

La idea de iniciar un estudio del mundo natural por la especie biológica que más puede interesar al alumno, que es la suya propia, parece al- 
tamente positiva. Su estudio puede servir, además, no sólo para comprender el mundo vivo, sino también para comprender lo que es la Ciencia como una parte de la Cultura.

El funcionamiento del organismo humano puede hacerse de una forma elemental y fundamental. El significado de sus funciones, la relación de éstas con las estructuras que las sustentan, la primacía de la función sobre la estructura, las adaptaciones de la especie humana a sus necesidades biológicas, al ambiente terrestre, etc.

Sin embargo, hay que reconocer que esa magnífica oportunidad está desperdiciada. El título «El ser humano y la salud» equipara un concepto pragmático, la salud, con el concepto fundamental, el ser humano, que, por cierto, debería enunciarse con un enfoque biológico correcto, es decir, la especie humana. El concepto de especie es fundamental en Biología, ¿por qué soslayarlo? El hombre es un ejemplo de especie animal, y sólo con este enfoque su estudio puede servir para entender el conjunto del mundo vivo.

En cuanto a la equiparación del concepto fundamental, la especie humana, con una de sus muchas derivaciones, significa romper la coherencia. El estudio del funcionamiento del organismo humano hará entender sus alteraciones y, por tanto, los conceptos de salud y enfermedad. Si se estudia lo fundamental todo lo demás vendrá por añadidura.

Una de las condiciones para un discurso racional -y parece lógico exigírselas a un currículo- es el mantener el mismo criterio a lo largo de todo el discurso, condición que en este caso no se cumple, como se evidencia en el lenguaje, que nos indica el criterio.

El contenido de «El ser humano..." se desmenuza en cinco puntos, con el nombre de 'conceptos', a pesar de que éstos son mínimos y se entremezclan con actividades (por ejemplo, identificación y localización de órganos y aparatos). El primero de estos 'conceptos' es «el hombre y la mujer», como seres vivos. La especie humana, el hombre como concepto biológico, la especie Homo-sapiens incluye inequívocamente a la mujer. El que en el conjunto de individuos que constituye la especie humana -como en cualquier otra- haya individuos del sexo masculino y del sexo femenino no afecta para nada a la comprensión del funcionamiento del organismo humano y de la situación de la especie humana en la Naturaleza. Otra cosa es el tratamiento de algo de tanto interés biológico como es el sexo, que está aquí abordado de forma confusa, no sólo en el concepto «el hombre y la mujer», sino más adelante en «la relación afectiva y sexual».

Este enunciado puede ponerse como ejemplo de confusionismo, de pseudociencia. La relación afectiva no es un asunto biológico, y se supo- 
ne que el tratamiento de la afectividad irá más allá del sexo. El hombre tiene otras dimensiones, además de las biológicas. Pero habrá que respetar una claridad de ideas, una claridad de niveles para entender esas dimensiones. Después de estudiar el hombre desde el punto de vista biológico, se pasa a otro nivel en el que entran en juego otras variables no biológicas, un nivel de mayor complejidad, con propiedades nuevas, con lenguaje nuevo: el nivel psicológico. De la misma manera, al considerar por encima del nivel biológico haciendo intervenir variables culturales, pasamos al nivel de la Antropología cultural.

Ciertamente, todas estas variables coexisten en el hombre, pero son susceptibles de separarse conceptualmente. Mezclarlo todo es el campo abonado para la pseudociencia. El estudio del sexo desde un punto de vista biológico, el interés que despierta en los alumnos y el que tiene, ciertamente, para entender el mundo vivo, exige un tratamiento serio. Como sucede con todos los aspectos biológicos, éste también es complejo pero, igual que con cualquier otro aspecto, podemos acercarnos a su complejidad por aproximaciones sucesivas.

Como siempre, podemos plantear la pregunta de su función en el mundo vivo, de su significado, y éste parece claro: el sexo aporta al mundo vivo variabilidad. Si se comparan las especies que se cruzan sexualmente con las que se reproducen por bipartición, la diferencia es patente. En estas últimas es donde realmente se produce una auténtica reproducción con identidad: las copias son idénticas al organismo progenitor. Las bacterias, por ejemplo, por bipartición originan clones, series de individuos idénticos, aunque hay también variación, pues la mutación es normal en todos los organismos y de vez en cuando hay errores en las copias. Pero, a partir de este error, a partir del individuo mutante se origina un nuevo clon, otra vez una serie de copias idénticas. En las especies que se reproducen sexualmente-como el hombre- no hay dos individuos iguales, a excepción de los gemelos idénticos, gemelos monozigóticos, originados por bipartición de un nuevo embrión.

Esta enorme variabilidad supone una inversión para el futuro, supone una reserva de nuevas posibilidades, no sólo como un reto al cambio del medio (una especie de margen de seguridad ante lo imprevisto), sino también para posibles perfeccionamientos. Pensemos en la homeotermia de aves y mamíferos, que supone una cierta independencia ante los avatares climáticos y que se ha seleccionado a partir de los reptiles, que vivían en el mismo medio. Las ventajas de la variabilidad no son sólo a largo plazo (en ese caso no se seleccionarían) sino también a plazo inmediato. Si un error en la copia es letal, es decir, supone la pérdida de algo 
fundamental para la vida, el hecho de tener otra dotación genética resulta muy favorable. Como dice Weiss (1975): «dos mejor que uno».

Puede entenderse, entonces, la razón del éxito de la sexualidad en el mundo vivo y de su evolución (incluso a formas diferentes, que pueden tener también ventajas en determinadas condiciones, como el hermafroditismo o la partenogénesis). Las complicaciones añadidas como pueden ser los caracteres sexuales secundarios y cortejos que aseguran el reconocimiento de individuos de distinto sexo pero de la misma especie (los híbridos son estériles), puede interpretarse desde este punto de vista del mantenimiento de la variabilidad. Otros muchos aspectos de la sexualidad muestran su significado a la luz de la Biología, como puede ser la cópula, tan importante, como se ha visto, en el ambiente terrestre.

Estas reflexiones sobre el sexo biológico nos indican que no puede estudiarse una especie biológica desconectada de las demás. Análogamente a cómo, al hablar de la lengua, Goethe dice que el que sabe sólo la suya ni siquiera sabe bien la suya, al estudiar el hombre son necesarios los demás seres vivos para contrastar las interpretaciones sobre el funcionamiento o las adaptaciones del organismo humano. Del resto de los seres vivos es de donde pueden tomarse los grupos de control para esas contrastaciones. Unas veces por su semejanza, cuando las variables consideradas sean las mismas; otras veces por sus diferencias, cuando esas variables sean otras.

Así, por ejemplo, la interpretación de que los párpados o las lágrimas o la piel queratinizada son adaptaciones al ambiente terrestre se contrastará con la ausencia de párpados o glándulas lacrimales en los peces y con la ausencia de piel queratinizada en anfibios y su presencia a partir de los reptiles.

Sin embargo, en el Decreto citado que establece el currículo de la Educación Primaria no se señala en ningún momento la necesidad de este estudio comparado, de esta relación entre el hombre y el resto del mundo vivo. Pero no es sólo esto. Si, repitiendo lo que se ha señalado al principio, el lenguaje denuncia el criterio, ¿qué comentario puede hacerse a esa mezcla de lenguaje biológico y lenguaje jurídico que se recoge en los contenidos del capítulo«4. Los seres vivos»?:

\section{LOS SERES VIVOS}

\section{Conceptos}

Los seres vivos: características básicas.

Los animales y las plantas como seres vivos. Diferencias. Interacciones entre los animales, las plantas y las personas.

Las principales plantas y animales del entorno próximo: morfología, alimentación, reproducción y respuesta ante los estímulos. 
Relaciones alimentarias entre animales y plantas.

Las plantas: árboles, arbustos y hierbas.

Los animales: vertebrados e invertebrados.

Importancia de los animales y plantas para las personas.

Procedimientos

Observación y registro sistemático del crecimiento de plantas y del desarrollo y formas de vida de animales.

Construcción y mantenimiento de terrarios, acuarios, etc.

Identificación de animales y plantas mediante la consulta de guías sencillas.

Elaboración de informes sencillos, sobre animales y plantas, integrando informaciones diversas (observaciones, consulta de libros, etc.).

Manejo de instrumentos sencillos para la observación de animales y plantas (pinzas, lupa binocular, etc.).

Actitudes

Interés por la observación y el estudio de los seres vivos. Respeto por los animales y plantas.

Responsabilidad en las tareas de mantenimiento y cuidados de animales y plantas en el aula y en el entorno escolar.

Respeto a las normas de uso, de seguridad y de mantenimiento de los instrumentos de observación y de los materiales de trabajo.

Sensibilidad por la precisión y el rigor en la observación sistemática de los animales y plantas y en la elaboración de los informes correspondientes.

Todos los llamados 'conceptos' de este «4. Los seres vivos», son un ejemplo de banalidad (plantas, árboles, arbustos y hierbas), antropocentrismo (vertebrados e invertebrados, importancia de los animales y plantas para las personas), pseudociencia (interacciones entre animales, plantas y personas), y, por supuesto, dogmatismo, ya que en ningún momento se habla de reflexionar, de interpretar, de buscar relaciones, etc. Parece claro que con el enfoque de este currículo difícilmente se enseñará a pensar, se desarrollará la creatividad en los alumnos, ni éstos experimentarán placer intelectual alguno.

Tampoco parece muy adecuada la preparación actual del Magisterio. Tenemos una deuda muy grave y de mucha responsabilidad con los maestros. Supongo que todos somos conscientes de que la preparación que reciben, para una función tan importante y compleja, es muy pobre. Por supuesto que ningún maestro, de ningún nivel de enseñanza, termina nunca de formarse: su formación dura lo que dura su carrera docente. Pero el andamiaje que se construye en el período de estudiante ha de tener cierta consistencia para soportar todo el edificio posterior. 


\section{Reivindicación de la Ciencia}

Estamos implicados en una empresa ciertamente compleja, aunque también muy hermosa. Debemos, pues, luchar para que nuestra tarea no se degrade y que de la Escuela puedan salir personas que sepan pensar, que sean creativas y valoren la Cultura y disfruten con ella.

\section{Bibliografía}

BARnes, N. S. y CuRTis, H. (1993): Biología. México: Panamericana.

Bunge, M. (1975): La investigación científica. Barcelona: Ariel.

DARWIN, C. (1859): El origen de las especies. Edición castellana de 1985. Madrid: Edaf. Existen otras ediciones en castellano, en Planeta Agostini, Espasa-Calpe, Bruguera, Debate, etc.

DARWIN, C. (1876): Autobiografía. Edición castellana de 1997. Madrid: Alianza.

LAMARCK, J. B. de (1809): Filosofía zoológica. Edición castellana de 1986. Barcelona: Alta Fulla.

MENDEL, G. (1866): «Experimentos sobre híbridos en plantas». En SINNOT, E. W. DUNN, L. C. y DOBSHANSKY, Th. (1961): Principios de Genética. Barcelona: Omega.

MONOD, J. (1985): El azar y la necesidad. Barcelona: Tusquets.

RUSSELl, B. (1983): La perspectiva científica. Barcelona: Ariel.

UNAMUNo, M. de (1917): “¿Sobre exámenes y reválidas?». Nuevo Mundo, 16 de noviembre. Se recoge en las Obras Completas, Tomo IX. Madrid: Escelicer.

UNAMUNO, M. de (1915): «Nuestros pedagogos». La Nación (Argentina), 10 de agosto. Se recoge en las Obras Completas, Tomo IX. Madrid: Escelicer.

Weiss, P. B. (1975): La Ciencia de la Biología. Barcelona: Omega. 